\title{
A failed platform: The Citizen Consensus Conference travels to Chile
}

Public Understanding of Science 2016, Vol. 25(4) 499-5II

(C) The Author(s) 2015

Reprints and permissions: sagepub.co.uk/journalsPermissions.nav DOI: $10.1177 / 0963662514561940$ pus.sagepub.com

(SAGE

\section{Sebastián Ureta}

Departamento de Sociología, Universidad Alberto Hurtado, Chile; Innovation in Governance Research Group, Department of Sociology, Technical University of Berlin, Germany

\begin{abstract}
This article starts by reviewing the setbacks that the recent Science and Technology Studies literature has identified in the functioning of technologies of democracy, the different arrangements that look to enact deliberation on technoscientific issues. Putting a focus on the Citizen Consensus Conference, it then proposes that several of these setbacks are related to the kind of "work" that these technologies are expected to do, identifying two kinds of it: performing a laboratory-based experiment and constituting a platform for the dissemination of facts. It then applies this framework to study a Citizen Consensus Conference carried out in Chile in 2003. After a detailed genealogy of the planning, implementation and afterlife of this exercise, the article concludes that several of the limitations experienced are derived from a "successful outcome" conceived as solely running a neat lab-based experiment, arguing for the need to incorporate its functioning as a platform with all the associated transformations and messiness.
\end{abstract}

\section{Keywords}

Chile, consensus conferences, experiments, platforms, technologies of democracy

\section{Introduction}

Nowadays, we rarely hear anyone either in the government or the scientific establishment denying the value of public involvement in technoscientific issues. On the contrary, "discourses of public participation in science have become virtually hegemonic" (Braun and Schultz, 2010: 403). As a consequence, "it no longer seems legitimate to think and work within the classical policy framework without including some kind of stakeholder involvement or public participation" (Felt and Wynne, 2007: 56). Therefore, the main question has become "no longer whether the public should have a say in technical decisions, but how to promote more meaningful interaction among policymakers, scientific experts, corporate producers, and the public" (Jasanoff, 2003: 238).

The most prominent answer to this last issue has been the development of "technologies of democracy" (Laurent, 2011), or devices specifically designed to properly incorporate lay people/ knowledge into technoscientific policymaking. From citizen's juries to planning cells, the last 
three decades have witnessed a flourishing of these devices, which have been adapted to deal with a multitude of issues and controversies. However, a review of the literature on the topic shows us an undeniable change of attitude toward them. From initially motivating an important degree of enthusiasm as the most sensible way to breach the distance between experts/policymakers and lay people, a growing amount of critical analyses have emerged in the last few years. The main point of such critiques has been the very limited impact that such exercises seem to have on concretely democratizing technoscience. A growing amount of scholarship on Science and Technology Studies (STS $)^{1}$ have identified as the main effect of such devices its very opposite: "a more subtle way of disciplining ... citizenship to make it more suitable to comply with technoscience advancements" (Bucchi and Neresini, 2008: 457-458). This is because "participation of this kind operates in an already constituted field of existing institutional coordinates which not only define a certain problem but also its potential participants" (Papadopoulos, 2011: 185).

None of these devices materializes better these tensions than the Citizen Consensus Conference (CCC). Developed in Denmark in the late 1980s, the CCC looked to enhance the participation of citizens in policymaking through their direct and informed discussion with experts about a particular issue (Grundahl, 1995). A key difference between the CCC and other technologies of democracy was that it was created and applied by the Danish Board of Technology (DBT), a public organization with close connections with the parliament. Theoretically, such a close connection ensured that the conclusions to be reached through particular CCCs were going to have an impact on policymaking. This was heightened by the premise that only issues that were controversial and/ or about to be treated in parliament were going to be dealt with through a CCC. Given this, and other characteristics (for a detailed overview, see Grundahl, 1995), this device rapidly became one of the most talked about technologies for democracy, being extensively applied in Denmark and elsewhere during the late 1990 s and early 2000 s. $^{2}$

This situation started to change from the mid-2000s. After being initially lauded as an example to follow (see the contributions on Joss and Durant, 1995), especially given its positive initial impact on the Danish political system (Joss, 1995, 1998), the device has been the focus of a growing amount of scholarly critique on STS in recent years (Blok, 2007; Bogner, 2012; Goven, 2003; Horst and Irwin, 2010; Jasanoff, 2003; Jensen, 2005; Laurent, 2011; Nielsen et al., 2007; Seifert, 2006). The points criticized are manifold: the expectation of consensus as the outcome of the exercise, a too rigid framing, the power of stakeholders and experts to guide the discussion, the process to select a right "issue," "citizens" and "experts" the political and media irrelevance of the results, the purely experimental nature of most implementations outside Denmark, and so on. Such critique was joined by an abrupt reduction in the enthusiasm for the instrument. In Denmark, the DBT suffered successive reductions in public funding with the result that they have not been able to organize another CCC since $2005 .^{3}$ A similar situation happened internationally, where a plethora of CCCs in early 2000s was followed by their virtual disappearance at the beginning of this decade.

Given this situation, it is relevant to ask whether there are reasons to keep the CCC or it is better to simply discard it as a relatively failed scheme. This second option seems tempting, but there is a catch. Many of the problems of the CCC are also the problems of the idea of deliberation in itself, a principle that is at the very heart of most (if not all) technologies of democracy. Therefore, to discard the CCC should also mean to move beyond them. Such a move would mean either to (1) return to the traditional deficit model of the public understanding of science or (2) to move somewhere else. The second alternative is interesting, but also fraught with dangers and uncertainties. For this reason, a radical rejection of deliberation could well lead to political impotence and fatalism rather than to the development of more effective forms to enhance technical democracy. Given this, and before moving in any direction, it is necessary to start by better understanding exactly what are the problems that CCCs faced when trying to fully enact deliberation at the heart of technoscientific governance. 
In order to contribute to this task, this article will analyze one particular application of this device: a CCC entitled "El manejo de mi ficha clínica de salud" ("the management of my patient's health record") carried out in Santiago, Chile, in November of 2003. ${ }^{4}$ In line with a previous paper by the author (Ureta, 2014), in dealing with this case, the question will not be whether the CCC "travels well" (Einsienel et al., 2001) or not (Nielsen et al., 2007; Seifert, 2006). Instead, the article will explore the kinds of work that the CCC does when traveling to a location like Chile in the early 2000s. Taking this approach offers two advantages from existing analyses on the travels of CCC. First, it allows the paper to move beyond the either/or options that pervade many of them. In its replacement, the aim is to show that CCCs are multiple entities, "enabling and restricting at the same time" (Braun and Schultz, 2010: 404). Second, by refusing merely to check whether the initial expectations were fulfilled or not, it opens up the analysis to the unexpected, to how the implementation of such schemes always implies the "unpredictable movement, of people and issues, and give[s] rise to forms of social responsiveness and articulations that spill over the models of interaction that organizers bring to bear" (Lezaun and Soneryd, 2007: 295). Both advantages, I believe, are necessary steps toward a deeper understanding of the shortcomings (and strengths) of current technologies of democracy.

More in particular, the work of CCCs is going to be understood simply as the differences that the implementation of $\mathrm{CCC}$ causes in a determinate location and time. In this respect, the existing STS literature on technologies of democracy identifies two main kinds of work that CCCs might do: performing a laboratory-based experiment and constituting a platform for the dissemination of certain facts.

First, and following the well-known tradition of laboratory studies in STS (for an overview see Doing, 2008), an important part of the literature identifies implemented CCCs as experiments. Such a denomination is derived, first, from the recognition that these exercises are always surrounded by uncertainty and "no method can guarantee their successful democratic outcome" (Jensen, 2005: 231). In second place, the experimental status is given by the recognition that such initiatives are usually "organized by professional participation specialists and carried out under controlled conditions" (Bogner, 2012: 507), similar to the ones to be found in any scientific laboratory. Inside such purified spaces, that bear little similarity to the conditions found outside, the entities to be included in the experiment (an issue, experts, citizens, etc.) are produced anew through "complex arrangements comprising literary, material and social elements" (Laurent, 2011: 651) and "charged with the task of demonstrating that the method can work" (Bogner, 2012: 507).

However, implementations of CCCs never look solely to work as successful laboratory experiments in democratic deliberation. There is always, at least in rhetoric terms, a second kind of work expected from their implementation: to constitute a platform for the transformation of a certain state of affairs beyond the particular setting (or laboratory) in which the CCC is carried out. Applying the term developed by Muniesa and Callon (2007) for the analysis of experiments in economics, a platform can be defined as a particular configuration that looks to remove some of the frames set in the laboratory in order to "overcome the distance that an experiment generates between the 'inside' and the 'outside' of the experimental setting" (p. 173) in order to generate strong commitments between the involved actors regarding the objectives and conclusions of the experiment. In particular, the $\mathrm{CCC}$ as platform looks to work as a demonstration of the possibility of materializing several key tenets of the deliberative turn: that technoscientific black-boxes can be opened to public scrutiny (Blok, 2007), that reflective citizens can actively engage with experts in fruitful discussions of technoscientific issues (Felt and Wynne, 2007), that consensus can be reached (Horst and Irwin, 2010) and it can have a decisive impact on the resolution of concrete technoscientific controversies (Laurent, 2011) with the final outcome of decisively contributing to the advance toward greater levels of technical democracy. As can be seen, such a list is quite ample, and not a little ambitious, and no single CCC could possibly expect to become a platform for its 
full demonstration, but at least some of these reasons/tenets are always present in the justifications given for the need to implement the device.

Obviously, these two kinds of work do not cover all the different ways in which a CCC might work when applied to a different context. Several other kinds of work that escape such classification might appear, some of them general, other specific to the case under analysis. For this reason, this framework will be taken only as a reference for the analysis of the case under study here. In the following sections of the article, I will make a genealogy of the Chilean implementation of CCC, specifically highlighting the main kinds of work associated with it and how they reflect the tensions associated with the proper materialization of technical democracy.

\section{Setting up the laboratory}

In November of 2001, the Pan-American Health Organization (PAHO) held a meeting in Sao Paulo, Brazil, to discuss with delegates from all over Latin America their plans for developing a virtual library on health issues among other topics. Among the people presenting was Amelia Rosas, a Spanish employee of the DBT who had been invited to introduce the CCC to the audience. After her presentation, the head of the PAHO unit in charge of the meeting talked about their belief that instruments such as the $\mathrm{CCC}$ were a possible way to truly democratize health policy in the region, adding that they would gladly support its concrete testing in one of PAHO's member countries. Esperanza Perez, the representative of Chile's National Council for Science and Technology (CONICYT), was enthusiastic about the potential of the instrument and promised to explore the possibility of running a $\mathrm{CCC}$ in Chile.

On her return to Chile, Perez started promoting the implementation of a CCC in Chile and managed to involve two key actors: Carmen Lozano, a doctor working at CONICYT with extensive networks to the Ministry of Health (MINSAL), and Margarita Arriagada, the newly appointed director of the Library of the Chilean Congress (BCN). For all of them, the CCC appeared to be a promising way to finally materialize the involvement of Chilean citizens into scientific deliberation, helping to reduce the democratic deficit perceived as characteristic of Chile at the time. After some further discussion, finally in June of 2003, an agreement was signed between MINSAL, BCN, and CONICYT to run a $\mathrm{CCC}$ in Chile with funding from PAHO and technical support by the DBT. ${ }^{5}$

In such an agreement, the CCC was understood as "a pilot experience for Chile and the region" whose ultimate aim was to "test the methodology [CCC] and transfer it to other organisms and sectors interested in using it to evaluate technologies with social impact." Thus, from the very beginning, the CCC was expected to work both as an experiment and a platform. First, it was seen as an experiment because of the novelty of the implementation, as well as the fact that the whole process would be under the continual and systematic observation of several organizations, Chilean and international. Second, the success of such experiment was always tied to the Chilean CCC also working as platform, mainly in the sense of helping to mobilize in Chile and Latin America the very particular kind of democratic deliberation of technoscientific issues enacted by a CCC.

Regarding the first kind of work, the starting point was to enact an "experimental community" (Bogner, 2012) formed by all the different entities who were necessary to conduct the experiment. As long stated by laboratory studies (Knorr Cetina, 1981; Latour, 1987), these entities were not simply going to be mobilized into the lab from somewhere else, but fully enacted inside it, constituting purified versions of the ones existing outside the laboratory. So the setting up of an experiment always involves "an operation of transformation and reduction: objects are 'purified' in order to make them fit for manipulation and production of controlled information" (Muniesa and Callon, 2007: 170).

In doing this, the members of the organizing committee had a clear script to follow: a document summarizing in a step-by-step fashion the stages developed by the DBT to implement a successful conference (PAHO, 2002). This document affirms that running a successful CCC depends on the 
enactment of three entities: a relevant technoscientific issue, a group of experts on it, and a group of citizens without knowledge and interests in the issue that could participate and produce the final document.

Regarding the first entity, a technoscientific issue, during June of 2003, several possibilities were considered (such as transgenic food, air pollution, emergency contraceptives, waste management, etc.) before the final selection of the modernization of the Patients' Health Records (PHRs). As affirmed by the committee's proceedings on 2 July 2003 (included as an appendix in Pino and Elizalde, 2004), this topic was selected because it was a quite concrete theme, which still required definitions on the part of the authority and had an important technoscientific component, so requiring the contribution of experts for its resolution. Also, and centrally, there was a need to know the attitudes of the public about it given that it was one of the topics being included in the parliamentary discussions about a proposal to legislate about the rights of the health system's users. In all, the PHR appeared as quite close to the "ideal" issue identified by the DBT guidelines (p. 17).

However, there was one key aspect in which the selected issue was not so close to the ideal proposed by the guidelines: there was not a proper social controversy surrounding it. As recalled by Lozano,

The truth is that it [the PHR] was never too conflictive, I mean, there were tensions but it wasn't the same as with, to say something, abortion or euthanasia. When we discussed the issue the thing that we tried to do was [to find] an issue that was of relevance for the citizenry but that didn't cause too much strain, because what interested us was to use the method, to see if it worked, do you understand? Then if we started talking about abortion [the group] will end up exploding upon the air, along with the method, then [the PHR] was, between brackets, a little more aseptic [laughs] from a health perspective.

Therefore, this issue was selected above all as a way to test the functioning of the device and not for its relevance as part of an ongoing sociotechnical controversy, something quite usual in CCC implementations in countries different from Denmark (Bogner, 2012; Goven, 2003; Seifert, 2006). Then for the organizing committee, the most important thing was not the characteristics of the existing debate and controversy regarding the issue, but the fact that the issue was "at hand" (Seifert, 2006) and carrying an important degree of "asepticism" that appeared to increase the experiment's chances of being successfully implemented.

Once this issue was approved, a second task was to select the group of experts who were going to provide the technical inputs for the citizens' deliberations. A first step was taken on 10th July when in a meeting of the organizing committee, "a list of experts was proposed with a multidisciplinary focus." At first, five key areas of the PHR were identified: legal, ethical, managerial, medical, and computing. To each one, an expert was tentatively nominated and contacted, and the interested ones were invited to a meeting on 17th July. The group was finally composed of four doctors covering differing medical and managerial aspects of the record, a lawyer from the Doctor's Guild, and an expert in computing from the National Labor Security Association of Chile (ACHS). In all, it constituted a straightforward group of "scientific" experts, using the definition from the guidelines (p. 23), or people with technical expertise in the issue at hand. However, the guidelines also identified a second kind of experts: "opinion-setting" ones or people who "could be representatives of stakeholder organizations, people prominent in the arts, etc.," but they were completely absent from this process.

After they agreed to participate, the organizers asked them to submit an input stating their positions on the issue that was later transformed into a single document. The most remarkable thing about this document is how similar the experts' positions about the issue were. Without exceptions, all of them coincided about (1) the need to reform the existent PHR due to its multiple problems and (2) that the new PHR should be unified, standardized, and with national coverage. The only point in which there was a certain degree of discrepancy was about the accessibility of the PHR. 
While for some of them (mostly the ones working in the public health system), only the doctors should have the right to access the full contents of the PHR, others felt that the patients should also be able to access them. This document was sent to the members of the citizens' panel for their study in advance of the first preparatory weekend.

In third place, regarding the selection of people to form the citizen panel, it proved more difficult to apply the guidelines straightaway. First, and given the financial impossibility of bringing people from all over the country as recommended, only people from three central regions of the country would be invited to participate. A related divergence was about the diffusion of the call in these regions. The guidelines established that all citizens should have the right to participate in the conference, especially the ones who had no special connection with the issue and did not usually participate in these kinds of events. The strategy initially pursued by the organizing committee was at odds with such a mandate, planning to distribute the call only to people who had already a certain connection with the health system, such as actors with a record of previous involvement in public consultations. When Rosas challenged this definition, they distributed also the call through other means (especially social workers at the borough level) receiving finally a large number of applications from a mixture of people with a history of connections with health issues and others who had shown no previous interest in these issues.

Once all the applications were received (almost 500), they selected the 16 members of the citizen panel based on their place of residence (using it as a proxy for their socioeconomic status), occupation, and demographic variables such as gender and age. In all, the group finally selected gave the impression to the committee of successfully representing in a certain way the whole "diversity" of the population of the three regions considered. Once these individuals were contacted and agreed to participate, finally the CCC could be properly run.

Up to this point, it is important to summarize which kind of work the CCC was doing in Chile. As seen in this section, such a work was focused mostly on enacting a laboratory in which the experiment could be run. First, there was the constitution of a clear "inside" formed by the actors and spaces involved in the planning of the CCC. Second, and centrally, the mobilization of the CCC's objects to this inside was not a mere relocation but a transformation. Especially in the case of the issue and the group of citizens, and to a lesser degree in the case of experts, the entities mobilized so far to the CCC were not "natural" objects but were specifically produced, or tailored, in the process of setting up the experiment. In doing so, digressions from the guidelines were inevitable. As the tensions between Rosas and the committee reveal, at several points, the enactment of the CCC's entities for the Chilean experiment challenged the guidelines developed by the DBT. All the compulsory entities were present (citizens, experts, issue, etc.) but in slightly different versions.

\section{Running the experiment}

The first instance in which this deliberative laboratory was put to work was on the two preparatory weekends held on October 3-5 and 24-26 of 2003. The first weekend mostly centered on giving the citizens information about the issue, so they could discuss and arrive at a first set of key subthemes that needed to be explored more in depth; a first basis for the future consensual document. Besides refining the issue, the weekend looked to start producing citizens out of the persons selected, in the understanding that "when selected, the members of the panel were not yet citizens that could deliberate; rather, they had to be made deliberative citizens through adequate techniques" (Laurent, 2009: 7).

The starting activity of the first weekend, carried out in a convention center outside Santiago, was for the citizens to introduce themselves and speak about their reasons to apply to the conference. In accordance with the guidelines, these "discussions and brainstorming sessions form the 
starting point for the discussion of key ideas" (p. 25) about the issue. In the Chilean case, the scenario set by the participants' introductions was quite different, as recalled by Rosas:

At the moment of expressing what had motivated them to participate in the conference the overwhelming majority talked about their desire to participate in decision-making and make their voices heard and they referred very little or none at all to the patient's record. They showed a great need to be heard and taken into consideration. This worry exists in all societies, citizens feel in general alienated in respect of decision making. However, this need is very intense in the case of Chile and possibly other countries of the region.

What can be inferred from Rosas' words is that the kind of citizen that first emerged from the Chilean CCC importantly diverged from the one in-scripted in the guidelines. Instead of being people who "voluntarily manifest an interest in the issue," (PAHO, 2002) for most of them the issue was irrelevant; it could have been any other and they would have applied anyway. What they really cared about was being considered as citizens. They answered the call because they wanted to make their voices heard; because of the promise made in the call for the $\mathrm{CCC}$ about their chance to actively participate in policymaking. For this reason, throughout the preparatory weekends extra effort was put into making the participants truly focus on the issue.

When doing so, the citizen's approach was remarkably similar to the one of the experts. For example, on the second day, and after some presentations by experts, they were asked to make a subdivision of the issue into relevant subthemes arriving at a list of seven areas. With the exception of the two additions (financial and political), the list was the same as the one provided by the experts in the preparatory meetings. Of these two additions, there is only evidence that the citizens explicitly demanded the financial aspect. Using this subdivision as a basis, on the second preparatory weekend, the citizens elaborated a set of key questions about the PHR that they were going to make to the experts in the proper CCC.

Finally, the proper CCC was carried out on 22-24 November. This time, the implementation explicitly looked to be transformed from a laboratory-based experiment into a proper platform. Such configuration was given, first, by devising a new space for the experiment. Instead of the lab-like location outside the city, the event was carried out in two very public buildings located in downtown Santiago, one of them the former National Congress. Second, attendance was open to any citizen wishing to do so and personal invitations were sent to all the 500 people who had applied to the original call. Third, the media, public authorities, and parliamentarians were personally invited. All these measures looked to establish "robust commitments" between the conclusions of the CCC and the different actors surrounding the issue, especially politicians, so that its results would really be taken into consideration in policymaking.

The first 2 days consisted mainly of the citizen panel first listening (Saturday) and then asking questions (Sunday morning) to 12 experts whose presentations covered the different subthemes of the issue in terms quite similar to the summary document. The contribution of this activity to the overall result of the $\mathrm{CCC}$, which was key on the original template, was weakened by two developments in this case. First, as noted by Pellegrini and Zurita (2004), "the experts' talks were more general than they usually were [in Danish implementations] and not so focused on the citizens' questions" (p. 356). This poor quality of the exchange was attributed to both the organizers (for not assigning specific questions to each expert) and the citizens (for making "diffuse" questions). Adding to this the absence of any written material, the final result was that the expert's input did not contribute much to the drafting of the final document.

On Sunday afternoon, the citizens were taken to a conference center in southern Santiago and put to work to arrive at a consensus about the issue and write the document summarizing it, a process that lasted until the early hours of Monday. The result was a 13-page document that starts by 
claiming that the current PHR is obsolete and needs a radical change. Then it proposes that, given that the health system is in a process of reform and several public offices are automatizing its work processes, the best solution is to replace the current PHR with what they called the Electronic Unique Health Record (REUS in Spanish). Beyond the acronym, there were few additions on the issue to the ones presented in the experts' inputs, just a selection between two of the competing positions presented: the electronic record and the right of the patients to access the PHR.

With the document at hand, the citizens were taken on the morning of Monday 24th of November to the closing act of the CCC, to be held in the National Congress building. After a welcoming speech from Arriagada, acting as project manager, the spokesperson of the citizen panel was invited to read the final document to an audience formed by authorities of MINSAL, parliamentarians, experts, a number of major media outlets, and general public. This moment had a strong emotional charge for the actors involved. There, standing in the main hall of the National Congress, was a man, a peasant from a rural area, speaking directly to the authorities on a matter of technical relevance such as the changes needed in the PHRs.

For most of them, especially the ones who had been involved from the very beginning such as Rosas, Prat, and Lozano (all of them present), it was the fulfillment of a long held expectation, even a dream. The CCC was finally delivering its promise; it did work as an instrument for the enactment of deliberative democracy. After traveling thousands of miles, it had produced the same result as in its point of origin: a well-crafted document in which a group of lay citizens summarized their points of consensus about a technical issue and then delivered it to the relevant authorities, experts, and policymakers.

\section{A (very) limited afterlife}

However, this moment also signaled the last proper work of the CCC in Chile, at least in the way it was predicted to do so. From now on, things started to increasingly diverge from the guidelines, affecting importantly the ultimate capability of the Chilean CCC to properly work as a platform in two of the main senses identified by the literature: transforming the issue and motivating further applications of the instrument.

Regarding the issue, the effect of the CCC on the reform of the PHR was null. Its recommendations were never considered in the further discussion of the issue, not even by the parliamentarians who were discussing the issue and whose library was the main organizer of the CCC. Such oblivion was derived from two characteristics of the process.

On the one hand, after the closing act, the document was mostly left alone to represent the position of the citizens. There were no further official publications, press conferences, or workshops to disseminate its contents. It just became a pdf uploaded to the conference's website, hoping for anyone with interest in the issue to find it while browsing on the web. Such an outcome was derived from the guidelines that stated that the document was to become the only embodiment of the consensus reached during the CCC. There was no other way out of the process. No other media such as an oral or audiovisual account, neither a derived organization nor demonstration on the part of the citizens, would be enough. Only the document. But documents are weak devices when they are left alone, especially in a country in which citizens' involvement in issues of their concern usually takes the form of direct public demonstrations. In this last sense, the document operated as an anti-political device (Barry, 2001), because it meant that any proper mobilization regarding the issue could be averted. Contrary to public demonstrations, in Chile, documents could be easily left aside. ${ }^{6}$

On the other hand, the irrelevance of the document was connected to a second key factor identified by Valenzuela: 
The final opposition [to the transformation of the PHR in the way proposed by the citizen panel] came from the health services, from the health professionals. ... The medical teams saw the traditional PHR as a matter of intellectual rights ... At the same time [in which the CCC was carried out] a project for a law on [patient's] health rights was being discussed and these very sensitive ethical issues were circulating in the agenda of the sector. Then, I think, the carrying out of this [CCC] was crisscrossed by a more general context and for this it is important to consider in which context you are going to locate your consultation; if it is going to be a trigger of conflicts and tensions or effectively it is going to be a quiet consultation, in which you can have the pure opinion of citizens ... I think this is what happened, because there were other processes developing in parallel and were not touched by this consultation, but they were implicit. For this [the CCC] is also interesting, because one thing is that you make it almost as inside a laboratory, controlling all the external variables, and other is that you make it in a context in which you are forced to consider all these contextual variables ...

This quote is very illustrative of two things. First, it shows the existence of a strong opposition on the part of the medical personnel at MINSAL to the opening of the PHR to the patients, the main position supported by the citizen panel. Given this, even if the document had been distributed among them, they would have probably blocked any attempt to implement its recommendations. A second, and most interesting, point refers to the connection between the CCC and this opposition. As Valenzuela recalls, at the time when the CCC was carried out, the issue of the PHR was being discussed as part of a broader law project regarding the patient's rights. On this discussion, the opposition of the medical personnel to the patients' access to the PHR was publicly made (for an example, see Vacarezza and Núñez, 2003). However, this critical position of the medical personnel was never openly presented in the CCC, neither by the experts nor in documents. As a result, at no point during the conference did the citizens have the opportunity to test or sharpen their position against it. On the contrary, most of the participating experts agreed, or did not openly oppose, the idea of the need of the PHR to be accessible to patients, and in this way it was included in the final document.

The question now is why this situation happened, why the publicly known position of such central actors was kept outside. One hint of an answer can be seen in the later part of Valenzuela's quote: the degree to which events happening elsewhere entered into the CCC laboratory. For her, the $\mathrm{CCC}$ was marred from the beginning by the deliberate exclusion of contradictory positions in order to avoid conflict. In this regard, we can recall the words of Lozano seen above: this issue was specifically selected for its lack of controversy, in order to test the instrument in a controlled environment. Therefore, if this lack of controversy was not out there, it should be produced in there. As a consequence, the issue was purified while mobilizing it inside the laboratory, leaving aside aspects that could potentially cause controversy. In doing this, we can see an "impulse to protect the experiment, to preserve the purity of its scientific and political meaning by insulating it from the forces of society at large" (Lezaun, 2011: 21). In this respect, the CCC was again "anti-political," in relation to refusing to allow a proper confrontation of contrasting positions. This depuration produced a neat experiment in which consensus was easily reached, but that had critical difficulties in working as a platform, especially when faced with the strong opposition of the MINSAL actors.

In parallel, this implementation also failed in the main aim set by its organizers: to work as a platform for the further usage of $\mathrm{CCC}$ as a concrete way to advance toward technical democracy in Chile and/or Latin America. In this respect, at the local level, there were some initial encouraging signs in the form of an interest on the part of actors from the citizen participation area of MINSAL to apply the instrument, as recalled by Soto: 
There was something they wanted to do afterwards, that the conference becomes something like a methodology that the MINSAL could use at local health centers ... but they wanted to make a modification in the methodology to simplify it, because it was too expensive ... and too long, they wanted to make a synthetized version of the conference, then we said "ok, let's work on a synthetized version, so the people don't have to sleepover at the place," but Amelia [Rosas] opposed it, she said to me "Martín, the methodology is what it is, it cannot be altered," then there was some tension with them, because they wanted by any means a simpler, cheaper, methodology.

In this quote, we can see the instrument behaving as what Latour (1987) has called an "immutable mobile" or a device that can travel to several places maintaining a certain internal structure, a certain integrity. In this case, Rosas acted as the enforcer of such integrity arguing that anyone wanting to enact citizen's consensus, and its related technical democracy, should implement the $\mathrm{CCC}$ in accordance with its guidelines and no digression was accepted. Given this immutability, and the important monetary and temporal investments it implied, the $\mathrm{CCC}$ was never again seriously considered as a tool to enact participatory processes inside the MINSAL.

Summing up, we can conclude that the Chilean CCC worked quite poorly as a platform. Beyond the emotional moment of the spokesperson reading the final document aloud, the key actors to whom this act was directed proved to be resistant to the reconfiguration of the citizens' role in policymaking that the CCC proposed. This problem reflects one of the main lessons of laboratory studies in STS: almost anything can be produced in a laboratory. The real challenge is to "raise a world" (Latour, 1983), to make a new order in which such objects are deemed to be true, existent. And in this sense, the Chilean CCC worked quite poorly, because it was unable to raise a world in which the two main facts emerged during its experimental phase (the transformations proposed in the issue and the effectiveness of CCC in enacting technical democracy) were accepted as valid.

\section{Conclusion}

Given what we have seen, we could conclude that the Chilean CCC contribution toward the advancement of citizen involvement in technoscientific issues in Chile or elsewhere in Latin America was minimal. Such an outcome, however, was not a consequence of the ultimate failure of the device, as some critics could rapidly conclude. On the contrary, it was, quite paradoxically, a direct consequence of its success, or, at least, its success in working finely in one of the ways outlined in the introduction: as an experiment on the deliberation of a technoscientific issue by group of lay citizens.

As seen above, from the very beginning, the actors involved were preoccupied (we could even say obsessed) with making the implementation of the CCC in Chile a "success." Contrary to the dual aim stated in the original agreement, in practice, such a success was understood solely as running a lab-based experiment on deliberative democracy in a way as similar as possible to the CCC guidelines. The notion of the Chilean CCC working also as a platform received little attention until the very end, when most of the actors involved bitterly complained about the limited afterlife of their well-crafted experiment. The rest of the time they adopted a mild version of technological determinism about this issue, implicitly assuming that a deliberative laboratory would automatically produce facts strong enough to be mobilized extensively. In parallel, in the few times in which the issue of the need to constitute a platform for the effective mobilization of facts was alluded (as in the closing ceremony), their approach was again to follow the DBT guidelines step by step. Any diversion from them was taken as producing different degrees of "false consensusing" (Horst and Irwin, 2010), and hence challenged. Such an approach, that was quite effective in terms of setting up a Danish-style experiment in deliberative democracy, had almost the opposite effect in relation to its working as a platform. Not only was the CCC never applied again on the continent, 
but also even the well-crafted facts produced about the PHR never appeared again in the subsequent discussion of the issue.

However, if we follow the proposals of the practitioners of laboratory studies, an alternative version of success emerges. From this perspective, the "success" of a device lies not in the correct application of the available templates, but in the production of facts strong enough to travel to multiple locations. And the production of such facts involves necessarily to lose respect of the guidelines, to understand scripts not as laws dictating strictly the entities to be involved and the limits of agency, but just a particular detention in a story of constant transformation. Immutability, as the one pursued in the case studied here, does not constitute an asset; on the contrary, it leads "to rupture, difference, and distance" (Law and Mol, 2001: 614). It leads to facts that cannot travel; that are so bounded to a particular location and time that they can only exist there. And the CCC ends up producing a parody of democracy, a small and secluded version of Danish democratic deliberation in the midst of the Chilean wilds.

Therefore, we can conclude from this case study that if there is still some hope for technologies of democracy such as CCC, such a future does not lie in running neat experiments in accordance with well-bounded scripts but must go in the direction of enacting multiple versions of experimental platforms, with all the mess and transformations that such a process entails. Such an option will need, following De Laet and Mol (2000), to enact more fluid versions of these technologies of democracy, "object[s] that ... [aren't] too rigorously bounded, that doesn't impose [themselves] but $\operatorname{tr}[\mathrm{y}]$ to serve, that [are] adaptable, flexible and responsive" (p. 226). It involves, in summary, to "make a mess" (Law, 2004) of the instrument in each particular location in which it is implemented in order to build up facts that are not only produced in a deliberative way but also can travel, from the laboratory to the several other relevant locations in which the issues at hand are being acted upon.

\section{Acknowledgements}

I acknowledge the very helpful comments on early drafts of this article by Jan-Peter Voß and the other members of the Innovation in Governance Research Group.

\section{Funding}

The underlying project "Innovation in Governance" (grant number 01UU0906) from which the fieldwork in which this publication derives was funded by the Federal Ministry for Education and Research (BMBF), Germany.

\section{Notes}

1. It is important to note that technologies of democracy such as Citizen Consensus Conference (CCC) have also constituted a main topic of research in policy studies and political science, an interest that has generated an ample literature (for some key references, see Goodin and Dryzek, 2006; Hendriks, 2002; Smith, 2009). However, the aim of this article is to specifically highlight how Science and Technology Studies (STS) analyses can contribute to our understanding of such devices, so other kind of literatures would be used only when necessary.

2. For a (relatively) updated list of CCCs, see http://www.loka.org/TrackingConsensus.html

3. Such reductions resulted in the Danish government cutting the fund altogether in 2011, allowing it to continue functioning but with funding coming from elsewhere.

4. This analysis will be based on material collected by the author while doing fieldwork in Chile between 2011 and 2012. Fieldwork consisted mainly of (1) 14 in-depth interviews with actors involved in the development of the Chilean CCC and (2) collection and analysis of several materials produced by the project in the form of research reports, papers, presentations, and so on. All the real names have been changed to protect the anonymity of the participants.

5. In practical terms, the implementation was going to be managed by an organizing committee composed by Perez and Lozano from National Council for Science and Technology (CONICYT), Arriagada, and 
María José Puelma (who acted as manager) from the Library of the Chilean Congress (BCN), and Estela Valenzuela from Ministry of Health (MINSAL).

6. Such an outcome was helped by the fact that the organizing committee rapidly disbanded after the conference without properly fulfilling the last task assigned to them by the guidelines on CCC: "to secure a diffusion of the final document and organize its further development through written materials and debates." This disbandment was centrally related to a lack of interest in the issue itself. As seen above, none of them had any special interest in the Patient Health Record (PHR), so it is understandable that they almost instantly deserted it after the experiment ended.

\section{References}

Barry A (2001) Political Machines, Governing and Technological Society. London: The Athlone Press.

Blok A (2007) Experts on public trial: On democratizing expertise through a Danish consensus conference. Public Understanding of Science 16: 163-182.

Bogner A (2012) The paradox of participation experiments. Science, Technology \& Human Values 37(5): $506-527$.

Braun K and Schultz S (2010) '.... Certain Amount of Engineering Involved': Constructing the public in participatory governance arrangements. Public Understanding of Science 19(4): 403-419.

Bucchi M and Neresini F (2008) Science and public participation. In: Hackett EJ, Amsterdamska O, Lynch ME, et al. (eds) The Handbook of Science and Technology Studies. Cambridge, MA: MIT Press, pp. 449-472.

De Laet M and Mol A (2000) The Zimbabwe bush pump: Mechanics of a fluid technology. Social Studies of Science 30(2): 225-263.

Doing P (2008) Give me a laboratory and I will raise a discipline: The past, present and future politics of laboratory studies in STS. In: Hackett EJ, Amsterdamska O, Lynch ME, et al. (eds) The Handbook of Science and Technology Studies, 3rd edn. Cambridge, MA: MIT Press, pp. 279-296.

Einsienel E, Jolsoe E and Breck T (2001) Publics at the technology table: The consensus conference in Denmark, Canada, and Australia. Public Understanding of Science 10(1): 83-98.

Felt U and Wynne B (2007) Taking European Knowledge Society Seriously. Geneva: European Commission.

Goodin RE and Dryzek JS (2006) Deliberative impacts: The macro-political uptake of mini-publics. Politics \& Society 34(2): 219-244.

Goven J (2003) Deploying the consensus conference in New Zealand: Democracy and de-problematization. Public Understanding of Science 12(4): 423-440.

Grundahl J (1995) The Danish consensus conference model. In: Joss S and Durant J (eds) Public Participation in Science: The Role of Consensus Conferences in Europe. London: Science Museum, pp. 31-41.

Hendriks C (2002) Institutions of deliberative democratic processes and interest groups: Roles, tensions and incentives. Australian Journal of Public Administration 61(1): 64-75.

Horst $\mathrm{M}$ and Irwin A (2010) Nations at ease with radical knowledge on consensus, consensusing and false consensusness. Social Studies of Science 40(1): 105-126.

Jasanoff S (2003) Technologies of humility: Citizen participation in governing science. Minerva 41: 223-244.

Jensen CB (2005) Citizen projects and consensus-building at the Danish Board of Technology: On experiments in democracy. Acta Sociologica 48(3): 221-235.

Joss S (1995) Evaluating consensus conferences: Necessity or luxury. In: Joss S and Durant J (eds) Public Participation in Science: The Role of Consensus Conferences in Europe. London: Science Museum, pp. 89-108.

Joss S (1998) Danish consensus conferences as a model of participatory technology assessment: An impact study of consensus conferences on Danish parliament and Danish public debate. Science and Public Policy 25(1): 2-22.

Joss S and Durant J (eds) (1995) Public Participation in Science: The Role of Consensus Conferences in Europe. London: Science Museum with the Support of the European Commission Directorate General XII.

Knorr Cetina K (1981) The Manufacture of Knowledge: An Essay on the Constructivist and Contextual Nature of Science. Oxford: Pergamon. Available at: http://cds.cern.ch/record/232962 
Latour B (1983) Give me a laboratory and I will raise the world. In: Knorr-Cetina K and Mulkay M (eds) Science Observed. London: SAGE, pp. 141-170.

Latour B (1987) Science in Action, How to Follow Engineers and Scientists through Society. Cambridge, MA: Harvard University Press.

Laurent B (2009) Replicating participatory devices: The consensus conference confronts nanotechnology. CSI Working Papers Series 18: 1-36.

Laurent B (2011) Technologies of democracy: Experiments and demonstrations. Science and Engineering Ethics 17(4): 649-666.

Law J (2004) After Method: Mess in Social Science Research. London: SAGE.

Law J and Mol A (2001) Situating technoscience: An inquiry into spatialities. Environment and Planning D: Society and Space 19: 609-621.

Lezaun J (2011) Offshore democracy: Launch and landfall of a socio-technical experiment. Economy and Society 40(4): 553-581.

Lezaun J and Soneryd L (2007) Consulting citizens: Technologies of elicitation and the mobility of publics. Public Understanding of Science 16(3): 279-297.

Muniesa F and Callon M (2007) Economic experiments and the construction of markets. In: MacKenzie D, Muniesa F and Siu L (eds) Do Economist Make Markets? On the Performativity of Economics. Princeton, NJ: Princeton University Press, pp. 163-189.

Nielsen AP, Lassen J and Sandoe P (2007) Democracy at its best? The consensus conference in a crossnational perspective. Journal of Agricultural and Environmental Ethics 20: 13-35.

Organización Panamericana de la Salud [Pan-American Health Organization] (PAHO) (2002) Conferencias De Consenso Ciudadano: Orientaciones Conceptuales Y Metodológicas [Citizen Consensus Conferences: Conceptual and methodological orientations]. Washington, DC: PAHO.

Papadopoulos D (2011) Alter-ontologies: Towards a constituent politics in technoscience. Social Studies of Science 41(2): 177-201.

Pellegrini A and Zurita L (2004) Evaluación Preliminar de La Primera Conferencia de Consenso Ciudadano de Chile [Preliminary evaluation of the first Citizen Consensus Conference in Chile]. Revista Panamericana de Salud Publica 15(5): 351-357.

Pino AM and Elizalde R (2004) Primera Conferencia de Consenso Ciudadano "El Manejo de Mi Ficha Clínica de Salud" [First Citizen Consensus Conference, 'The management of my Patient Health Record']. $22 \mathrm{Al}$ 24 de Noviembre 2003-Informe Final. Santiago: Biblioteca del Congreso Nacional de Chile.

Seifert F (2006) Local steps in an international career: A Danish-style consensus conference in Austria. Public Understanding of Science 15(1): 73-88.

Smith G (2009) Democratic Innovations: Designing Institutions for Citizen Participation. Cambridge: Cambridge University Press.

Ureta S (2014) 'Because in Chile [carbon] Markets Work!' Exploring an experimental implementation of an emissions trading scheme to deal with industrial air pollution in Santiago. Economy and Society 43(2): 285-306.

Vacarezza R and Núñez E (2003) A Quien Pertenece La Ficha Clínica? [Who is the owner of the Patient Health Record?] Revista Médica de Chile 131(1): 111-114.

\section{Author biography}

Sebastián Ureta is Associate Professor in the Departamento de Sociología at Universidad Alberto Hurtado (Chile). He works on the study of public policy, mixing Science and Technology Studies with poststructural theory on power and politics. He is currently finishing a monograph on the location of human beings in transport infrastructures (to be published by the MIT Press) and starting a new research project on the governance of mining waste in Chile. 